\title{
Apresentação do Dossiê: Intelectuais e resistências ao autoritarismo na América Latina
}

Carolina Amaral de Aguiar ${ }^{1}$

Fernando Camacho Padilla ${ }^{2}$

Em junho de 2009, a América Latina foi palco da deposição do presidente de Honduras Manuel Zelaya, fruto de uma decisão do Parlamento apoiada pelo Judiciário de seu país. O episódio foi considerado por muitos como um golpe de Estado pelo fato de Zelaya ter sido retirado sem direito à defesa, numa decisão sumária. Três anos depois, foi a vez do presidente paraguaio, Fernando Lugo, passar por um rápido processo de impeachment, levado a cabo pelo Senado, em um julgamento no qual não pôde se defender. Em 2016, um novo impeachment abalou a democracia no continente: Dilma Rousseff foi destituída do cargo de presidente pelo Parlamento após ser acusada de cometer as chamadas "pedaladas fiscais". Durante a simbólica votação ocorrida em 17 de abril na Câmara dos Deputados, que abriu o caminho para o impeachment, o então deputado Jair Bolsonaro evocou o torturador Carlos Brilhante Ustra em seu voto pela deposição, com a intenção de exaltar a ditadura da qual Russeff havia sido vítima. Em 2018, o mesmo Bolsonaro foi eleito presidente do Brasil, alcançando um resultado considerado improvável há poucos anos. Um ano depois, na Bolívia, Evo Morales renunciou ao cargo de presidente, que ocupava há treze anos, diante da violência e convulsão social derivadas da denúncia de fraude eleitoral. Sua sucessora, Jeanini Áñez, assumiu numa sessão legislativa sem quórum e, recentemente, foi presa acusada de tramar um golpe de Estado. Todos esses eventos, ao que pesem suas particularidades, podem ser

\footnotetext{
${ }^{1}$ Doutora em História Social pela Universidade de São Paulo (USP). É professora adjunta da Universidade Estadual de Londrina (UEL). E-mail: amaral_carol@yahoo.com.br.

2 Doutor em História pela Universidad Autónoma de Madrid (UAM) e pela Pontificia Universidad Católica de Chile (PUC). Atualmente, é professor do Departamento de História Contemporânea da UAM. E-mail: fernando.camacho@uam.es.
} 
apontados como exemplos de tensões nas democracias latino-americanas, mostrando que certas conquistas consideradas consolidadas após as transições democráticas das últimas décadas do século XX seguiam frágeis.

Por outro lado, é necessário ter em conta que a emergência de uma nova direita com traços autoritários a partir da década de 2010 não é exclusividade da América Latina. As redes sociais ajudaram a impulsionar a capacidade de mobilização de partidos de extrema direita em países da Europa Ocidental e Oriental (cresceu vertiginosamente em Polônia, Hungria, Eslovênia, Itália, Alemanha, Espanha, Suécia, entre outros). Em 2016, a eleição de Donald Trump levou à presidência dos Estados Unidos um candidato representante dos valores da extrema direita e que soube polarizar " [...] intencionalmente o ambiente político como parte da estratégia de campanha, recorrendo às tensões étnicas e raciais fundantes da sociedade americana.” (GOLDSTEIN, 2019, p. 18). A nova direita - na qual também se insere o atual presidente brasileiro, Jair Bolsonaro -, porém, parece dar uma nova forma a velhos discursos. Como coloca Ariel Goldstein, há uma "reconstrução idealizada do passado ao qual prometem um retorno" (2019, p. 19), como mostram o lema trumpista "America great again" ou o slogan nacionalista do governo Bolsonaro "Pátria amada, Brasil".

Diante deste cenário, o dossiê "Intelectuais e resistências ao autoritarismo na América Latina” propõe uma reflexão historiográfica de longa duração sobre o uso de noções como autoritarismo e resistência por meio do estudo de como elas aparecem em momentos específicos do século XX latino-americano. Apesar de ambas estarem presentes e serem utilizadas em análises de diferentes épocas, contextos nacionais e experiências, elas permanecem ativas na tentativa de compreender as complexas articulações políticas que se dão, no presente, na América Latina. Este dossiê também pretende contribuir para o entendimento da historicidade do autoritarismo e da resistência enquanto dimensões e categorias: apesar da permanência dos seus usos, esses termos são mobilizados para designar processos políticos bastante variados.

\section{O debate sobre o autoritarismo na América Latina}


Em seu extenso estudo sobre os regimes não democráticos, Juan J. Linz (2000) afirma que a definição de um regime como "autoritário" depende do grau ou do tipo de limitação ao pluralismo que promove, assim como do grau de apatia e desmobilização políticas nas quais se baseia. Já o totalitarismo se diferenciaria de outras formas autoritárias por um conjunto de características específicas, como a presença de um centro de poder monístico, de uma exclusiva e mais ou menos elaborada ideologia utilizada por um grupo, um líder ou um partido para conseguir legitimação e de uma participação cidadã mobilizada em prol dessa ideologia. Assim, Linz (2000) vai na direção oposta à de Hannah Arendt (2013) no que concerne a defesa de que os regimes totalitários contariam com um apoio passivo das massas. A partir dessa definição, pode-se perceber que a dificuldade de se firmar definições consensuais sobre o autoritarismo e suas formas de apresentação é acompanhada das constantes revisões impostas pelas experiências históricas que demandam dos autores adaptações conceituais.

Para além das fronteiras necessárias que criam diferenciações entre tipos de regimes autoritários, muitas vezes a dificuldade de rotular aparece num estágio anterior, ou seja, no momento de definir o que é e o que deixa de ser autoritarismo. Pedro Estevam Alves Pinto Serrano (2016) mostra como os limites entre Estado de direito e Estado autoritário na América Latina são tênues. Mesmo nos casos em que a acunha Estado autoritário pode ser usada sem ressalvas, caso dos regimes adeptos da doutrina de Segurança Nacional do Cone Sul, seus governos encontraram brechas jurídicas para alcançarem certa legitimação institucional. Esses regimes chegaram ao poder sob o argumento da defesa do Estado e da nação e procuraram mecanismos que os situaram no limite entre a legalidade e a ilegalidade. No caso da ditadura argentina, por exemplo, Victoria Crespo (2008) analisa como o chamado Processo de Reorganização Nacional se constituiu como uma tentativa jurídico-política de legitimação da repressão. $\mathrm{O}$ marco jurídico se mostra, portanto, insuficiente para determinar a presença do autoritarismo nas sociedades latino-americanas. $\mathrm{O}$ quadro se torna ainda mais complexo quando consideramos os episódios recentes de Honduras, Paraguai, Bolívia e Brasil que abrem este texto, nos quais a deposição dos presidentes eleitos não se deu por meio de golpes 
militares, mas sim, majoritariamente, por decisões parlamentares respaldadas pelos sistemas judiciários desses países.

A tentativa de legitimar-se no poder por parte dos regimes ditatoriais no Cone Sul foi tão bem sucedida, em alguns casos, que gerou outra chave de reflexão historiográfica relevante: o legado autoritário que restou do passado nas sociedades democráticas contemporâneas. O caso mais emblemático, nesse sentido, é o processo de revisão constitucional pelo qual passa o Chile neste momento. A ditadura de Augusto Pinochet se preocupou de tal modo em dar um caráter legal ao seu regime que, além de aprovar uma nova constituição em 1980, tornou extremadamente árdua a tarefa de modificá-la, amarrando o estatuto jurídico nacional. Mais de trinta anos depois da redemocratização, a recente eleição para Convenção Constitucional Chilena, ocorrida em maio de 2021, criou as condições para a elaboração de uma constituição que promete eliminar de maneira definitiva a herança autoritária pinochetista. Trata-se, portanto, de uma experiência que constitui um marco histórico na América Latina e no mundo.

Para além dos elementos legais, é importante investigar a permanência do autoritarismo em governos contemporâneos em outras esferas. No plano discursivo, por exemplo, é possível destacar características autoritárias em governos como os de Trump ou de Bolsonaro quando verificamos a necessidade de evocar o discurso do "inimigo" interno. Como coloca Serrano: "O discurso do autoritarismo sempre encontra guarida no projeto de "salvação nacional"” (2016, p. 146). As forças políticas de extrema direita da atualidade reciclam, em grande parte, construções culturais e ideológicas presentes e disseminadas na segunda metade do século XX, em tempos de Guerra Fria, como a noção de "ameaça comunista". Naquele período, como coloca Marina Franco (2012), o combate ao comunismo internacional, levado a cabo pelos Estados Unidos, reverberou na América Latina na forma de políticas autoritárias e repressivas.

Porém, se é possível identificar pontos discursivos comuns entre os atuais representantes do pensamento autoritário e aqueles perpetrados pelas ditaduras militares, convém considerar que o campo da extrema direita atual passa por reformulações e abriga novos atores, como destacam Ernesto Bohoslavsky e Magdalena Broquetas (2019): os think tanks, as igrejas neopentecostais, os novos movimentos conservadores, entre outros. 
Além disso, se a figura do inimigo interno segue desempenhando um papel central, no entanto, é empregada para designar novos grupos - Bohoslavsky e Broquetas dão como exemplo a luta de Bolsonaro contra o "comunopetismo" ou o apelo do Círculo Militar uruguaio durante a campanha de Luís Lacalle Pou para o voto "contra o marxismo".

O termo autoritarismo foi usado para descrever distintos governos na história da América Latina no século XX. Guillermo O’Donnell colocou diferentes contextos políticos latino-americanos sob a denominação de "Estado Burocrático Autoritário". Para o autor, o autoritarismo estaria ligado a projetos nacionalistas que procuraram impulsionar as indústrias nacionais, o que faria com que o conceito abarcasse desde o Estado mexicano instaurado pela Revolução até às ditaduras dos anos 1960. No horizonte de O’Donnell, que recebeu duras críticas quanto à sua tipologia ${ }^{3}$, está a crise do populismo que serviria de explicação para a emergência de governos que deixaram de buscar uma legitimação nos setores populares. Por outro lado, líderes populistas não escaparam do rótulo de autoritários por parte da historiografia quando flertaram com o nazi-fascismo e seus mecanismos de atração das massas, como ocorreu com o Estado Novo brasileiro ou como sustentam leituras acerca do início do peronismo ${ }^{4}$. Governos de esquerda tampouco estiveram alheios a revisões históricas que os consideraram autoritários pela falta de eleições direitas ou pela pouca transparência em processos eleitorais, como ocorreu diante dos rumos tomados pela Revolução Cubana ou das seguidas reeleições de Hugo Chávez e Evo Morales.

\section{Resistências ao autoritarismo}

Apesar da necessidade de situar o escopo deste dossiê em distintos contextos históricos que podem ser considerados autoritários, esta proposta não se dedica, porém, a definir o autoritarismo na América Latina. O foco está, na verdade, no outro lado da moeda, na chamada resistência. Em vários momentos em que os governos foram

\footnotetext{
${ }^{3}$ Sobre as críticas e revisões que o próprio O’Donnell fará do conceito de Estado Burocrático Autoritário ver RICUPERO, 2014.

${ }^{4}$ Um exemplo dessa abordagem pode ser encontrado em CAPELATO, 2009.
} 
considerados autoritários, grupos de oposição se organizaram em torno da noção de que as limitadas opções jurídicas-institucionais que o autoritarismo delega aos cidadãos os obrigam a encontrar formas diversas de resistir. O lema da resistência apresenta também um amplo espectro temporal e geográfico. É possível nele abrigar os movimentos antifascistas dos anos 1920 e 1930 ou a articulação contra as ditaduras do Cone Sul nos anos 1960 e 1970. São diversos, igualmente, os formatos e as maneiras pelos quais os resistentes se manifestaram ao longo do século XX: a produção intelectual, o campo cultural, a diplomacia, as brechas político-legais, os protestos de rua e a luta armada. Como se percebe nos textos que compõem este dossiê, muitas vezes esses modos de resistir se entrecruzam, especialmente quando se analisa a atuação dos intelectuais - outra noção conceitual bastante ampla, que pode abarcar escritores, artistas, juristas, políticos, entre outros atores.

Assim, faz-se preciso considerar, brevemente, os usos históricos do conceito de resistência. Conforme ressalta Marcos Napolitano, a resistência ganha sua "carga semântica e o sentido político" (2017, p. 28) mais definitivos na Segunda Guerra Mundial. O historiador destaca, assim, que o uso atual desse conceito surge como oposição ao nazifascismo - ou seja, à forma mais acabada e inquestionável do autoritarismo. É inevitável, portanto, pensar a resistência a partir do entendimento que o termo adquire com o paradigma da Resistência francesa e a memória constituída na França sobre o período de ocupação nazista (1940-1944), como coloca Denise Rollemberg (2016, p. 18). Portanto, o ato de resistir é entendido como uma reação ao Estado autoritário: "A flexibilidade do conceito de resistência parece diretamente proporcional ao grau de sucesso do Estado em sua ambição totalitária. Assim, quanto mais bem sucedido na ambição totalitária o regime for, mais flexível é a conceitualização de resistência a ele.” (ROLLEMBERG, 2016, p. 19).

No caso das ditaduras de Segurança Nacional dos anos 1960 e 1970 na América Latina, o uso do termo resistência se consagrou para definir os mecanismos de oposição aos regimes. No entanto, como mostra Marcos Napolitano em seu estudo sobre a resistência à ditadura brasileira (2017), há um entendimento elástico desse termo que englobou grupos muito distintos nessa categoria, dos adeptos da luta armada aos liberais. 
O mesmo autor ressalta que a flexibilidade do conceito é o que permite seu uso ampliado: "Nesta experiência histórica, as várias resistências antifascistas congregam ideologias diferenciadas e até conflitantes - liberalismo, comunismo, cristianismo e o socialismo sob a mesma bandeira da defesa da dignidade humana e da liberdade pública." (NAPOLITANO, 2017, p. 28).

$\mathrm{Na}$ última década, o debate sobre autoritarismo e resistência se mesclou a uma preocupação historiográfica maior: qual foi a participação da população civil em contextos autoritários na América Latina? Ora vista como vítima, ora como cúmplice, a sociedade civil deixou de ser analisada como um todo homogêneo para que a categoria "resistência" pudesse ser entendida em suas especificidades. Como mostram Ozias Paese Neves e Vinícius Liebel (2015), o debate sobre se os golpes e/ou as ditaduras seriam civilmilitares ou apenas militares não encontrou, até o presente momento, um consenso. Outro ponto de interesse recente foi a questão dos distintos modelos de transição democrática (que, segundo os autores, têm no caso argentino seu viés mais rupturista e no brasileiro o mais aproximado à noção de abertura; "abertura lenta, gradual e segura"). Esses modelos ajudam a refletir sobre como os pactos sociais realizados no contexto de redemocratização estão relacionados à maior permanência do autoritarismo nas sociedades latinoamericanas contemporâneas. Assim, entender a resistência, sua dimensão real ou mitológica, também passou a ser um modo de compreender até que ponto a sociedade civil aceitou conviver com certos legados do autoritarismo ditatorial em nome de uma pretensa coesão social. A fragilidade dessa coesão, no entanto, estaria justamente na tensão entre memória e esquecimento que parece se esgarçar a cada dia, como mostra o atual contexto político brasileiro.

Portanto, um dossiê dedicado a abrigar estudos sobre as resistências - em seu caráter plural - ao autoritarismo na América Latina deve, antes de tudo, abrir espaço para uma diversidade de temáticas, períodos e contextos nacionais (ou transnacionais) que procuram dar conta da elasticidade do conceito quando aplicado ao continente. Não se trata, porém, de abrir mão do rigor conceitual: ao contrário, busca-se entender o conceito a partir de suas múltiplas aplicações. Os artigos aqui apresentados analisam experiências específicas nas quais autoritarismo e resistência se encontraram. Muitas vezes esse 
encontro não se deu apenas no campo do embate Estado versus cidadão, mas em batalhas ideológicas travadas pelos intelectuais latino-americanos. Tampouco se pode entender autoritarismo e resistência sem pensar em outros temas delicados e complexos da história das ideias que perpassam esse debate, como articulação política, redes de sociabilidade, publicações, solidariedade, exílio, entre outros.

\section{Contribuições do dossiê}

Pelas razões expostas, os artigos que compõem o dossiê se destacam pela variedade de formas de interpretar o conceito de resistência, bem como pela diversidade de espaços geográficos e temporalidades que abordam. Em "Intelectuais brasileiros sob a mira da censura franquista", por exemplo, a autora Gabriela de Lima Grecco analisa a circulação editorial entre América Latina e Europa durante o franquismo (1936-1975), com foco nos títulos brasileiros que sofreram censura da ditadura espanhola. A autora analisa também a triangulação realizada por editoras latino-americanas (especialmente argentinas) na difusão da literatura produzida no Brasil na Espanha, que inicialmente contribuiu para uma aproximação literária entre as duas nações. Porém, a circulação de ideias nesse espaço transatlântico esbarrou na política de censura autoritária do franquismo, que barrou autores como Jorge Amado, Graciliano Ramos e José Lins do Rego.

O meio editorial é tema de outros textos que compõem o dossiê. Se no artigo de Gabriela de Lima Grecco esse meio é vítima direta do autoritarismo, em "Entre primaveras e tempestades: a Editorial Universitaria de Buenos Aires e o violento começo da década de 1970 na Argentina”, de Caio Henrique Vicente Romero, o mercado editorial é mostrado como um campo de batalha em um momento de violência política crescente que antecede o golpe de 1976. Analisando uma época em que o meio universitário foi palco de tensões causadas por diferentes grupos peronistas e não peronistas, o autor tem como objeto de estudo a editora EUDEBA, da Universidade de Buenos Aires. O alinhamento do corpo editorial com o peronismo de esquerda fez com que a editora fosse alvo de ataques da Triple A e passasse por uma série de agitações institucionais. Assim, 
o estudo sobre os embates que envolvem a editora no início dos anos 1970 ajudam a entender um momento de escalada do autoritarismo na sociedade argentina.

Outro texto que elege o meio editorial como lugar de exercício da resistência é "Editar desde el exilio: los Informativos CELATS-ALAETS como ejercicio de resistencia (1976-1985)”, de Maria Josefina Lamaisón. A autora pesquisa a publicação de um Centro ligado à Asociación Latinoamericana de Escuelas de Trabajo Social, localizado em Lima, que se apresentou como um ponto de convergência para trabalhadores sociais latinoamericanos num momento em que as ditaduras do Cone Sul geraram experiências massivas de exílio. O CELATS reuniu, assim, brasileiros, chilenos, colombianos, venezuelanos e peruanos que discutiram, em suas publicações, problemas do marxismo. Assim, os Informativos levados a cabo por esse centro se consolidaram como espaços de expressão de exilados privados dos canais de comunicação em seus países de origem. Também se configuraram como um veículo de formação de uma rede latino-americana mais ampla na área do Trabalho Social.

Ainda elencando textos que se dedicam à história intelectual e à circulação de ideias, vale destacar o artigo "A influência teórica do militante espanhol Abraham Guillén em grupos de luta armada na América Latina”, de Carla Luciana Silva. A autora se dedica ao repertório conceitual que sustentou a luta armada no continente durante o período das ditaduras de Segurança Nacional no Cone Sul por meio de um estudo que recupera a importância de Abraham Guillén nesse contexto. $\mathrm{O}$ anarquista espanhol participou de lutas políticas no Uruguai, na Bolívia e na Argentina. Porém, num momento em que o latino-americanismo buscava integrar as táticas revolucionárias nas distintas regiões do continente, suas ideias chegaram também a revolucionários brasileiros, como Carlos Lamarca e Carlos Marighella, por meio do intenso contato que alguns deles terão com a esquerda chilena gerado pela experiência do exílio. O artigo busca, portanto, encontrar novas referências teóricas e inéditas triangulações para o entendimento da circulação de ideias em meio aos grupos que se opuseram às ditaduras no Cone Sul.

Ainda em meio a novos estudos sobre a circulação de ideias no interior da América Latina e do mundo hispânico, o texto "Inspirações anarquistas de Nicanor Parra e Octavio Paz”, de Sebastião Leal Ferreira Vargas Netto, explora de modo comparado a obra de 
dois autores latino-americanos renomados que pertencem a uma mesma geração: o chileno Nicanor Parra e o mexicano Octavio Paz. O autor entende a noção de resistência de forma ampla, ligando-a à vertente libertária do anarquismo. Por meio da apreciação da obra poética desses dois nomes importantes do pensamento latino-americano, o artigo explora o antiautoritarismo que perpassa a atuação de Parra e Paz ao longo do tempo, apesar de críticas e acusações que ambos receberam à esquerda e à direita em suas trajetórias biográficas.

Trabalhando com a noção de "resiliência nas artes", Diego Renart González aborda em seu artigo "Resiliencia artística en Ciudad Trujillo: el antitrujillismo en las artes dominicanas a mitad de siglo" o longo período da ditadura de Rafael Lónidas Trujillo na República Dominicana (1930-1961). O autor estuda as formas de resistência do campo artístico, levadas a cabo por intelectuais dominicanos e por exilados europeus radicados no país, com foco nas ações empreendidas pelas artes visuais. A noção de resiliência permite uma compreensão ampla dos distintos grupos que compõem o circuito das artes no período: dos simpatizantes do regime aqueles que foram assassinados pela repressão. Assim como outros textos do dossiê, o autor analisa as obras produzidas nesse contexto e sua relação com as formas de resistência ao autoritarismo.

Por fim, o dossiê se encerra com um artigo dos pesquisadores Fernando Camacho Padilla e Moira Cristiá: "La resistencia cultural a las dictaduras del Cono Sur. Un estudio comparado de la solidaridad desde Francia y Suecia con Chile y Argentina a partir de la gráfica política (1973-1990)". Por meio de um enfoque transnacional (que articula os países do Cone Sul com as democracias ocidentais europeias) e comparado (presente nos estudos de caso de Suécia e França, por parte da Europa, e Chile e Argentina, por parte da América Latina), os autores apresentam uma análise ampla do campo cultural vinculado às denúncias de violações de direitos humanos nos anos 1970 e 1980. As redes de solidariedade internacionais se articularam para receber exilados e apoiar suas causas, em um contexto em que as democracias ocidentais, como França e Suécia, se encontravam sensibilizadas pelos debates contrários às experiências autoritárias que marcavam a história recente da Europa, as mobilizações estudantis, o apoio aos movimentos de libertação nacional. No entanto, apesar dos pontos comuns que marcaram 
essas experiências de exílio, os autores analisam as particularidades das sociedades de acolhida francesa e sueca, bem como as diferenças entre os exílios argentino e chileno.

Essa breve apresentação dos textos que compõem o dossiê mostra a ampla gama de interpretações que a dicotomia autoritarismo $x$ resistência alcança na história recente latino-americana. No entanto, as aproximações entre eles são evidentes. Os textos mostram uma predominância de estudos marcados pelo transnacional, indicando que ambos os fenômenos (Estados autoritários e redes de oposição) envolveram colaborações entre sujeitos no interior da América Latina e entre a América Latina e a Europa. O estudo dos pontos de contato entre os distintos contextos nacionais é particularmente interessante para se pensar autoritarismo e resistência nos domínios da História das ideias e da História cultural. Em termos metodológicos, os textos enfatizam a análise de trajetórias biográficas e de veículos de circulação de ideias, sejam eles obras artísticas, livros ou documentos oficiais. Assim, longe de esgotar as possibilidades de entender o tema dos "Intelectuais e resistências ao autoritarismo na América Latina", este dossiê parece indicar possíveis novos caminhos de abordá-lo. Nos textos aqui presentes, essas amplas categorias se apresentam como balizas na escolha de objetos bem delimitados e conjuntos de fontes documentais pouco estudadas que lançam, por sua vez, novos desafios para a compressão conceitual da noção de resistência.

\section{Artigos e resenhas deste número}

O presente número da Revista Eletrônica da ANPHLAC traz ainda outras contribuições que corroboram a trajetória desta publicação como um espaço de diversidade temática, metodológica e de abordagens que mostra as várias possibilidades que concernem o estudo da História da América. A seção Artigos se inicia com o texto “Arielismo, politica e religião nos escritos de José Enrique Rodó sobre os Estados Unidos", de Fabio Muruci dos Santos, que revisita o clássico Ariel (1900), do uruguaio José Enrique Rodó, analisando a crítica à religiosidade estadunidense como um dos pontos que levam o autor a rechaçar os Estados Unidos como modelo para os países latino-americanos - vistos, por Rodó, como baluartes dos valores católicos. 
Na sequência o número publica o texto "Documentos de inteligência como fonte: o caso do Federal Bureau of Investigation (FBI)", de João Paulo Martins Faria. Trata-se de uma reflexão sobre os aspectos que os historiadores devem levar em conta ao utilizarem como fonte os documentos de agências de inteligência, particularmente aqueles do FBI. O autor utiliza como objeto documentos dos anos 1950 e 1960, período em que o órgão se ocupou dos movimentos sociais estadunidenses. Nesse contexto, o FBI produziu uma farta documentação alinhada ao discurso supremacista branco, o que coloca dilemas morais e particularidades no uso dessas fontes pelos pesquisadores.

Em “As políticas públicas de esporte e a transição para o socialismo em Cuba (1959-1965)", de Renato Beschizza Valentin, o autor analisa as políticas esportivas da Dirección General de Deportes (DGD), que foi substituída em fevereiro de 1961 pelo Instituto Nacional de Deportes, Educación Física y Recreación (INDER). O recorte temporal do artigo vai da vitória da Revolução Cubana em janeiro de 1959, quando o órgão é criado, até 1965. O texto estuda a implantação das políticas públicas para o esporte em Cuba considerando sua relação com as distintas etapas de consolidação da própria Revolução e do socialismo.

"Exílio e polêmicas intelectuais em Mariel Revista de Literatura y Arte (1983 1985): notas para um debate", de Pacelli Dias Alves de Sousa, tem como objeto de estudos a revista literária e cultural Mariel Revista de Literatura y Arte. Essa publicação, levada a cabo por exilados e refugiados cubanos, circulou entre a Flórida e Nova Iorque e pode ser considerada uma reposta ao quinqüenio gris e ao endurecimento do controle da liberdade de expressão em Cuba. $\mathrm{O}$ autor elabora uma análise que busca desvendar o discurso de Mariel considerando, de forma articulada, sua sintaxe própria e seu potencial como fonte histórica.

O artigo "Quando o "bello sexo" se conecta: reflexões de Soledad Acosta de Samper sobre o ensino das mulheres no Congreso Pedagógico Hispano-PortuguésAmericano (1892)", de Thaís Mendes Moura Carneiro, dedica-se ao estudo da intelectual colombiana Soledad Acosta de Samper a partir de sua participação no congresso que aparece no título, ocorrido em 1982 em Madri. Nessa ocasião, ela proferiu uma comunicação sobre o papel do Estado para o ensino profissionalizante das mulheres. 
Assim, a autora valoriza a participação de Acosta de Samper com base em seu papel ativo nas redes de sociabilidade que conectavam América Latina e Espanha, predominantemente masculinas.

Por fim, encerramos a seção Artigos com "Walter Rodney: Intelectual Socialista e Historiador da África", de Iuri Cavlak, também inserido no campo de estudos da História Intelectual. Cavlak estuda, especificamente, a obra Como a Europa Subdesenvolveu a África de autoria desse intelectual nascido na Guiana Inglesa. A trajetória de Rodney mostra seu engajamento e seu papel como mediador entre três continentes: América, Europa e África. Sua intensa circulação foi fundamental na consolidação de seu legado intelectual e político, tornando-o um exemplo de integração entre pensamento intelectual e lutas sociais.

Além dos artigos já apresentados, o novo número da Revista Eletrônica da ANPHLAC publica três resenhas de livros recentes que mereceram destaque entre as novas contribuições para a História da América: Luis Guilherme Assis Kalil escreve sobre o livro de Bruno Silva, As cores do Novo Mundo: degeneração, ideias de raça e racismos nos séculos XVII e XVIII (Lisboa: Lisbon, 2020); Flávio Vilas-Bôas Trovão resenha Utopias latino-americanas: políticas, sociedade e cultura, organizado por Maria Lígia Coelho Prado (São Paulo: Contexto, 2021); e Tatiana de Aquino Mascarenhas analisa as contribuições de Gabo, cronista da América: história, memória e literatura, de Felipe de Paula Góis Vieira (São Paulo: Intermeios; Campinas: Unicamp, 2020).

Desejamos, finalmente, uma boa leitura deste número, que mantém a excelência que a Revista Eletrônica da ANPHLAC apresenta desde sua criação, e que faz dela uma das principais publicações acadêmicas na área de História da América publicadas no Brasil.

\section{Referências bibliográficas}

ARENDT, Hannah. Origens do totalitarismo: Antissemitismo, imperialismo, totalitarismo. São Paulo: Companhia das Letras, 2013. 
BOHOSLAVSKY, Ernesto; BROQUETAS, Magdalena. "Las derechas en América Latina tras la salida de las últimas dictaduras". Historia y problemas del siglo $X X$, ano 10 , v. 11, jul./dez. 2019. Disponível em:

<https://ojs.fhce.edu.uy/index.php/cont/article/view/603>. Acesso em: 11 mai. 2021.

CAPELATO, Maria Helena Rolim. Multidões em cena: propaganda política no varguismo e no peronismo. São Paulo: Editora Unesp, 2009.

CRESPO, Victoria. "Legalidad y dictadura". In: LIDA, Clara E.; CRESPO, Horacio; YANKELEVICH, Pablo (org.). Argentina, 1976: estudios en torno al golpe de Estado. Buenos Aires: Fondo de Cultura Económica: El Colegio de México, 2008.

FRANCO, Marina. Anticomunismo, subversión y pátria. Construcciones culturales e ideológicas en la Argentina de los 70. In: CALANDRA, Benedetta; FRANCO, Marina (Org.). La guerra fría cultural en América Latina. Buenos Aires: Biblos, 2012.

GOLDSTEIN, Ariel. "A ascensão da direita radical brasileira no contexto internacional”. In: BOHOSLAVSKY, Ernesto; MOTTA, Rodrigo Patto Sá; BOISARD, Stéphane (org.). Pensar as direitas na América Latina. São Paulo: Alameda, 2019.

LINZ, Juan J. Totalitarian and Authoritarian Regimes. Boulder; Londres: Lynne Rienner Publishers, 2000.

NAPOLITANO, Marcos. Coração civil: a vida cultural brasileira sob o regime militar (1964-1985) - ensaio historiográfico. São Paulo: Intermeios, 2017.

NEVES, Ozias Paese; LIEBEL, Vinícius. "Os regimes militares no Brasil e na América do Sul - Historiografia e Perspectivas". Revista Eletrônica da Anphlac, n. 18, jan./jul. 2015. Disponível em: <https://revista.anphlac.org.br/anphlac/article/view/2277>. Acesso em: 11 mai. 2021.

O’DONNELL, Guillermo. Modernización y autoritarismo. Buenos Aires: Paidós, 1972.

RICUPERO, Bernardo. "Da estrutura à agência: momentos da interpretação de Guillermo O' Donnell sobre o autoritarismo latino-americano". Crítica e sociedade, v. 4, n. 2, 2014. Disponível em:

<http://www.seer.ufu.br/index.php/criticasociedade/article/view/26116>. Acesso em: 11 maio 2021. 
ROLLEMBERG, Denise. Resistência. Memória da ocupação nazista na França e na Itália. São Paulo: Alameda, 2016.

SERRANO, Pedro Estevam Alves Pinto. Autoritarismo e golpes na América Latina. Breve ensaio sobre jurisdição e exceção. São Paulo: Alameda, 2016. 